\title{
A representação do conceito de ativismo nos programas de informação dos canais de serviço público de televisão em Portugal
}

\author{
Naíde Müller \\ Faculdade de Ciências Humanas, Universidade Católica Portuguesa - 134517001@alunos.lisboa.ucp.pt
}

\section{Sumário}

$\mathrm{O}$ ambiente digital trouxe novas e inesperadas formas de mobilização coletiva e de ativismo, mas a televisão continua a ser o meio privilegiado para ter acesso à informação da grande maioria dos cidadãos, em Portugal e na Europa. Partindo-se da análise do conteúdo noticioso das peças que os jornalistas identificam como sendo sobre ativistas e ativismo, ou seja, que usam as palavras "ativistas" e "ativismo", na informação televisiva dos dois canais públicos da televisão portuguesa - RTP1 e RTP2 - no ano de 2017, foi possível aferir quais os assuntos cobertos e as causas com maior representatividade que são de âmbito internacional e relacionadas fundamentalmente com ques- tões políticas e de direitos humanos. Sendo práticas sociais dotadas de uma grande mutabilidade as ações ativistas são também alvo de uma volátil projeção mediática, no entanto, foi possível observar que os programas informativos da televisão pública não destacam a ação dos grupos ativistas que praticam atos violentos, privilegiando ações concretas no terreno, cujos porta-vozes são os cidadãos comuns ao nível social micro. Os resultados possibilitam uma reflexão sobre qual o papel da televisão pública, num momento em que procura justificar a sua relevância, no alcance da massa crítica por determinados grupos minoritários.

Palavras-chave: Ativismo, televisão, causas, representações.

\section{The Representation of the Concept of Activism in the Information Programs of Public Television channels in Portugal}

\begin{abstract}
The digital environment has brought new and unexpected forms of collective mobilization and activism, but television remains the privileged medium to access information of the vast majority of citizens in Portugal and in Europe. Based on content analysis of TV news reports that journalists identify as being about "activists" and "activism", news reports where

they use the words "activist" and "activism", in the television information of the Portuguese public channels - RTP1 and RTP2 - in 2017 , it was possible to determine which subjects were covered and the most representative causes that present an international scope and are fundamentally related to political and human rights issues. It was possible to obser-
\end{abstract}


ve that the public television news programs do not highlight the action of activist groups that practice violent acts. Special emphasis was placed on concrete actions on the ground, whose spokespersons are ordinary citizens at the social micro level. The results allow a reflection on the role of public television, at a time when it seeks to justify its relevance, in helping certain minority groups to reach critical mass.

Keywords: Activism, television, causes, representations.

\section{INTRODUÇÃOO}

Recentemente têm-se verificado mudanças sociais significativas pelo facto de os ativistas contemporâneos passarem a poder organizar-se de forma global deixando de estar limitados aos seus locais de ação (Baer, 2016; Bennett, 2014; Castells, 2017; Earl \& Kimport, 2011). Mas será que estas mudanças decorrentes do ativismo digital resultam em ferramentas efetivas para exponenciar ao máximo o poder da imaginação dos ativistas contemporâneos e a sua capacidade de intervir na mudança social? Se, por um lado, alguns autores defendem que estamos a assistir a um revivalismo de algumas formas de ativismo com o cultivo de fortes narrativas criativas sobre temas tão diversos como o combate à pobreza, poluição, racismo, com foco no clima e na justiça económica e social (Cardoso, Costa, Coelho, \& Pereira, 2015; Jordan, 2002; Jouët, 2018), por outro lado, o ativismo online tem sido criticado por não ser seguido ou complementado por formas de participação offline e muitas vezes rejeitado como clicativismo ou slacktivismo (Gladwell, 2011; Halupka, 2014; Karpf, 2010; Morozov, 2009; Shulman, 2009), cumprindo supostamente apenas o desejo de auto satisfação instantânea e tendo pouco ou nenhum impacto nos processos políticos reais e nas ações concretas dos cidadãos.

Também em Portugal se têm verificado mudanças sociais decorrentes da era da "comunicação em rede", com o ambiente digital a trazer novas e inesperadas formas de mobilização coletiva e de ativismo (Campos, Viera, \& Mendonça, 2016; Cardoso, et al., 2015). Mas a televisão continua a ser o meio privilegiado da grande maioria dos cidadãos, em Portugal e na Europa, para ter acesso à informação (Burnay e Ribeiro, 2016; EB88, 2017) e os noticiários televisivos influenciam fortemente, pela sua 
A representação do conceito de ativismo nos programas de informação dos canais de serviço público de televisão em Portugal

representatividade, a construção e orientação da opinião pública (Brandão, 2010, p. 134).

Partindo-se da análise do conteúdo noticioso das peças que os jornalistas identificam como sendo sobre ativistas e ativismo, na informação televisiva dos dois canais públicos da televisão portuguesa - RTP1 e RTP2 -, no ano de 2017, este artigo explora as associações que são feitas aos conceitos nos espaços informativos do serviço público de televisão e procura pistas sobre quem são os ativistas representados, que espaço ocupam, que causas defendem e sobre a atual imagem mediática televisiva a eles associada e transmitida aos públicos.

\section{O CONCEITO DE ATIVISMO}

Não existe uma definição universalmente reconhecida de ativismo e, apesar de ser um conceito amplamente utilizado em vários contextos, a literatura sobre este tópico, de um ponto de vista conceptual, é escassa. Etimologicamente a palavra ativismo é recente, surge no século XX, utilizada em contextos apolíticos e mais associada a questões metafísicas (Joyce, 2014). Na Europa, o termo foi usado para se referir ao "mundo físico de nações, poder e política" sendo que, no discurso sobre a Primeira Guerra Mundial, o ativismo foi usado por um jornalista britânico para descrever o apoio ativo à Alemanha. Nos anos 30, o termo continuou a denotar um envolvimento com a vida pública, mas não apenas em contextos políticos, uma vez que os educadores usaram o termo ativismo para se referirem à defesa de uma nova filosofia pedagógica. Durante os anos da Segunda Guerra Mundial a palavra ativismo é pouco mencionada, mas, na década de 1950, surgiu uma definição de ativismo que combinou a conotação do início do século XX de "crença política apaixonada" e a conotação da era progressiva do envolvimento pessoal na transformação social (Joyce, 2014, p.15). O conceito adquire os contornos contemporâneos passando a significar o "envolvimento pessoal em atividades que trazem transformação política e social", sendo que os investigadores da década de 60 construíram os seus estudos sobre este significado (Joyce, 2014, p. 16).

A definição de ativismo da Enciclopédia do Ativismo e da Justiça Social diz-nos que "o ativismo é uma ação em nome de uma causa, que vai além do que é convencional ou rotineiro" (Martin, 2007, p. 19). De um ponto de vista histórico o ativismo desempenhou um papel importante no fim da escravidão, desafiando as ditaduras, 
protegendo os trabalhadores da exploração, protegendo o meio ambiente, promovendo a igualdade para as mulheres, opondo-se ao racismo e a muitas outras questões importantes, no entanto, o ativismo também pode ser usado para outros objetivos como atacar minorias ou promover a guerra, pelo que o ativismo não é necessariamente algo bom ou mau. Tudo depende da causa, das ações e da apreciação de cada indivíduo sobre aquilo que "vale a pena" defender (Martin, 2007, p. 19).

A ação ativista vai, habitualmente, além da política convencional, no entanto, quando são criados partidos políticos para promover causas especiais, tais como partidos trabalhistas em muitos países nos séculos XIX e XX ou partidos verdes a partir da década de 1960, o ativismo transforma-se em política convencional passando a operar "lado a lado". O que conta como ativismo depende do que é convencional. Em sociedades nas quais a liberdade de expressão é respeitada e protegida, fazer queixas do governo é uma ocorrência rotineira. Mas numa ditadura tais queixas podem ser vistas como subversivas podendo os responsáveis ser punidos. Normalmente são aqueles que detêm menos poder na sociedade que recorrem ao ativismo uma vez que aqueles que detêm posições de poder e influência podem geralmente alcançar os seus objetivos através dos meios convencionais (Martin, 2007, pp. 19-20).

Tim Jordan (2002) afirma que as batalhas políticas tradicionais estão a ser substituídas por práticas coletivas que originam diferentes tipos de um novo ativismo político, contrariando as escolas de pensamento que afirmam que a cultura ocidental nunca foi politicamente mais apática. Nesta perspetiva, as sociedades do século XXI estão a gerar novos significados sobre o que é "uma vida boa" e esses novos significados estão a ganhar autoridade e a afetar o quotidiano (Jordan, 2002, p. 8).

O que separa o ativismo de outros tipos de ação coletiva, como partilhar a mesma sala de cinema, é a solidariedade que une os ativistas em torno do objetivo comum de alcançar mudanças na procura de novos valores para as sociedades do futuro. Historicamente, o conceito tem estado muito associado à ação conjunta com a motivação de alcançar mudanças políticas. Sendo que o próprio conceito de ação política incorpora diversas dimensões e uma vasta série de ações estando também a sofrer alterações nas sociedades ocidentais, algumas relacionadas com a habitual distinção de esquerda, centro e direita, que se tem apresentado como problemática quando apresentada às novas gerações enquanto separação ideológica estanque (Jordan, 2002). Por outro lado, o ativismo é muitas vezes confundido enquanto componente de uma cidadania ativa, sendo remetido para formas mais amplas de envolvimento com a comunidade, apesar de este envolvimento não possuir muitas vezes uma natureza 
A representação do conceito de ativismo nos programas de informação dos canais de serviço público de televisão em Portugal

ativista, funcionando apenas para abrir espaço para projetos comunitários dentro dos critérios definidos para um bom status de cidadania (Kennelly, 2009, pp. 135-145).

As diferentes abordagens e definições do ativismo estão relacionadas com o facto de o "ativista" representar uma "identidade negociada". Pesquisas anteriores fornecem pistas sobre como os atores de movimentos ativistas contestam as definições e desafiam a autoidentificação sobre que é ser "ativista" (Bobel, 2007; Corrigall-Brown, 2012; Gamson, 1995). Para auxiliar na compreensão das construções culturais concorrentes sobre o que é um "ativista" e o que eles fazem, as descobertas de Cortese (2015) permitiram a criação de três tipos de "ativistas" - Empáticos, Reconciliadores e os Demarcadores. Os Empáticos definem "ativista" de formas muito positivas e identificam-se com um tipo ideal de ativista. Estes atores dos movimentos geralmente definem um padrão de ativismo na organização e são os líderes que têm uma profunda dedicação aos objetivos e resultados do movimento. Os Reconciliadores constroem uma nova definição de "ativista" com o objetivo de conciliar a sua dedicação à missão do movimento, apesar da sua incapacidade de alcançar um "padrão perfeito" de ativismo. Os Reconciliadores estabelecem os seus próprios padrões de ativismo para que quase tudo o que fazem os qualifique como "ativista". Os Demarcadores têm definições claras sobre o que é um "bom ativista" e um "mau ativista", identificando-se entre os bons, e definindo uma fronteira objetiva entre ativistas. Agem como uma espécie de sentinela para se demarcarem do "mau ativismo" ou "ativismo radical" e usam esta demarcação para gerir perspetivas e táticas divergentes nos grupos ou movimentos onde se inserem (Cortese, 2015, p. 217).

Existem também vários métodos de ativismo. Gene Sharp (2005) divide os métodos de ação não violenta em três tipos principais. Primeiro, os métodos de protesto $e$ persuasão que vão além do comportamento convencional, como discursos, slogans, cartazes, protestos, vigílias, cantos, marchas e palestras. O segundo tipo de ação não violenta é a não-cooperação, desobediência aos costumes sociais, emigração de protesto, boicote dos produtores, retiro de depósitos bancários, embargo comercial internacional e uma ampla variedade de greves. O terceiro tipo é a intervenção, incluindo ocupações não-violentas, teatro de guerrilha, jejum e a criação de instituições económicas e políticas alternativas (Sharp, 2005, pp. 25-30). Entre a ação não violenta e a luta armada está a violência contra objetos físicos como, por exemplo, a sabotagem de oleodutos ou de plantações geneticamente modificadas (Martin, 2007, p. 21).

Os métodos de ativismo continuarão a evoluir juntamente com as oportunidades políticas e os desenvolvimentos culturais e tecnológicos. Para desafiar a cultura 
consumista, por exemplo, surgiu uma nova prática denominada culture jamming, que envolve uma transformação dos símbolos convencionais, como os usados em campanhas publicitárias, para criar uma mensagem nova, subversiva e de confronto (Klein, 2002, p. 201). O aumento do ativismo anticorporativo ou antibranding está relacionado, essencialmente, com fortes preocupações económicas e humanas e com a "quebra de promessas das marcas" (Klein, 2002, p. 201). Os protestos criativos surgem aqui como uma necessidade de "reforçar a estética das manifestações", numa tentativa de reduzir a carga estereotipada em torno dos movimentos e fazer com que as suas mensagens cheguem a públicos que de outra forma seriam inalcançáveis. Para isso são necessárias estratégias de comunicação integradas, com recurso a práticas das áreas do Marketing, Publicidade, Design e Relações Públicas que partilham um "lado artístico-transgressor" (Assis, 2006, p. 5). O ativismo online, denominado de ciberativismo, é outra das novas formas de ativismo e envolve a utilização da Internet para comunicar e organizar ações tradicionais. Não obstante o reconhecimento do potencial destas formas de ativismo, têm surgido perspetivas céticas sobre a capacidade da Internet e dos media sociais para fortalecer a democracia e servir como plataformas para a participação política (Fuchs, 2013, p. 10).

\section{Media e Democracia}

No momento atual de rápidas e constantes mudanças torna-se necessário examinar a forma como os estudos de media podem contribuir para procurar respostas para os dilemas éticos, políticos e sociais sempre em expansão. Não estando os estudos de media dissociados da cultura podem abordar esses dilemas perguntando, entre outras questões importantes e relevantes: Quem são os grupos e/ou indivíduos que estão ativamente envolvidos nas questões sociais urgentes atuais e de que forma eles ocupam, ou procuram ocupar, o espaço público na sua função de resistência a forças culturais mais amplas e estabelecidas? O presente artigo pretende ser um contributo para este debate, partindo do pressuposto de que, numa democracia saudável, a esfera pública exige que os dilemas sociopolíticos urgentes sejam objeto de contestação pública vigorosa como a fornecida por grupos ativistas (Benhabib, 1996).

Não é possível conhecer um país sem pensar nas suas revoluções. O historiador André Canhoto Costa (2019) recorda-nos que cultural e historicamente Portugal "parece ter sido vítima de uma instabilidade permanente, gerando revoluções atrás de revoluções, nenhuma com profundidade suficiente para inverter o processo de pobreza relativa" na comparação com os países do Norte da Europa (Costa, 2019, p. 19). Mesmo 
os vários movimentos que provocaram a erosão das hierarquias sociais têm-se revelado incapazes de gerar lideranças que façam com que as revoluções em Portugal atinjam os níveis de mudança social profunda alcançada por países como a França, Inglaterra ou os EUA. O autor apresenta, no entanto, a imprensa como o "instrumento da comunicação da efervescência das ideias que é fundamental para quebrar hábitos e conceitos antigos ou tradicionais" (Costa, 2019, pp. 39-42).

Quando falamos de meios de comunicação não falamos apenas de tipos de tecnologia e partes dos conteúdos que escolhemos, falamos de uma visão que reconhece que as utilizações e apropriações dos media penetram todos os aspetos da vida contemporânea (Deuze, 2011, p. 137). Sobre as dinâmicas dos pesos e contrapesos existentes no espaço público, que são ampliadas ou silenciadas através dos media, Elisabeth Noelle-Neumann (1974) defendeu que os que detêm as opiniões maioritárias no espaço público tendem, mesmo que indiretamente, a silenciar os que detêm as opiniões minoritárias que, por receio de represálias, acabam por não expor as suas ideias. De acordo com o mecanismo psicológico e social denominado "Espiral do Silêncio", os meios de comunicação de massa "devem ser vistos como criadores de opinião pública uma vez que fornecem o contexto ambiental ao qual as pessoas respondem com espontaneidade, concordância ou silêncio" (Noelle-Neumann, 1974, pp. 43-51). Para além disso, a autora salientou repetidamente a natureza dinâmica da opinião pública que, sendo limitada no tempo e no espaço, só está suscetível aos efeitos da espiral do silêncio durante um período de tempo (Noelle-Neumann, 1974, pp. 43-51). No âmbito da literatura que investiga a teoria da Espiral do Silêncio no contexto digital tem-se sublinhado que, mudanças na perceção do clima de opinião influenciam a predisposição das pessoas para expressar opiniões minoritárias (Matthes, 2015, pp. 155-156). De referir que os estudos sobre a observação dos pressupostos desta teoria no ambiente digital têm sugerido que as condições oferecidas facilitam a disponibilidade das pessoas para se manifestarem, parecendo diminuir o medo do isolamento, associado muitas vezes ao anonimato. No entanto, existem também evidências de que, apesar dos indivíduos parecerem estar mais dispostos a expressar suas afiliações políticas online, as discussões neste contexto são fortemente irracionais (Malaspina, 2014, p. 2).

Do ponto de vista do discurso democrático e de uma república participativa, a economia da informação em rede oferece uma verdadeira reorganização da esfera pública (Benkler, 2006, p. 465). No entanto, isso não significa que as funções básicas dos media tradicionais, enquanto instituições pilar das sociedades democráticas, 
deixem de ser de extrema importância, sendo vários os autores que alertam para os perigos reais e inerentes a um discurso e a uma perceção excessivamente otimista sobre os novos media e o que eles representam para as mudanças sociais em torno dos valores democráticos (Couldry, 2004; Curran, 2012; Sandoval \& Fuchs, 2010).

Tal como com o aparecimento da imprensa, a euforia da Internet nos anos 90 previa uma oportunidade para a marcha da democracia e que os ditadores iam cair porque a Internet inspirava e reclamava liberdade, mas muitos governos autoritários pelo mundo obtiveram, na prática, melhores ferramentas para censurar e alterar os conteúdos do que aquilo que os otimistas dos media digitais puderam prever (Curran, 2012; MacKinnon, 2011). Pelo que, sobre as 'afirmações apocalípticas' acerca desta matéria importa recordar que os novos e os velhos media estão a 'conviver' nas sociedades contemporâneas de forma articulada, com os novos a complementar os velhos (Ribeiro, 2015, p. 212).

Como resultado do desenvolvimento da indústria de tecnologias emergentes de novos media, a relação entre a televisão, a vida quotidiana e as audiências foi alterada gerando novos conceitos como o de "televisão transmedia" que se refere à "prática (...) de utilização de várias tecnologias de media para apresentar informação relativa a um único universo ficcional através de uma variedade de formas textuais" (Evans, 2011,p. 1).

Sobre a pertinência de se investigar a televisão neste contexto social e comunicacional, importa realçar que embora existam perspetivas que acreditam que a reconfiguração mediática trazida pelo ambiente digital fará com que a televisão deixe de ser, no curto ou médio prazo, um meio de comunicação social relevante, principalmente entre os mais jovens, as evidências apontam para um cenário de complementaridade (Vicente, 2016).

Apesar de se prever até 2023 um declínio na indústria tradicional de televisão por assinatura no mercado norte-americano (o maior do mundo), devido à ascensão do streaming, à incapacidade dos emissores públicos para alcançar aumentos significativos nas receitas e aos fortes desafios de competitividade colocados a outros players historicamente fortes (Global Entertainment \& Media Outlook 2019 - 2023), o que compromete o seu domínio quase absoluto no mercado, a televisão continua a ter uma "grande centralidade na vida social (usos do tempo, costumes e partilha social) e económica (peso no bolo publicitário, canal de distribuição para as indústrias criativas)", continuando a ser o "ícone dos media tradicionais por excelência" (Cardoso et al., 2016, p. 9). 
A televisão em Portugal de uma forma geral, e os canais generalistas em particular, procuram adaptar-se à conjuntura de convergência dos media e de transformação tecnológica, sendo que o seu estudo continua relevante quer pelas incertezas decorrentes da digitalização, quer pelo impacto que estas mudanças têm na reorganização do setor e nas novas práticas de consumo audiovisual (Cardoso, Mendonça, Paisana, Lima, \& Caldeira, 2017; Sobral, 2012).

Para além de continuar a ser o meio privilegiado da grande maioria dos cidadãos, em Portugal e na Europa, para ter acesso à informação (Burnay \& Ribeiro, 2016; EB88, 2017; Cardoso et al., 2017; Gonçalves, 2015), a análise da evolução dos consumos nos últimos 17 anos, indica que, a par do crescimento progressivo do Cabo, no Prime-time (horário nobre), destaca-se o crescimento dos géneros temáticos "Informação", "Séries" e "Entretenimento" (Cardoso et al., 2017, p. 26). De destacar também que o género "Informação" aumentou audiências na SIC, TVI e no Cabo, sendo que perdeu audiências em ambos os canais públicos RTP. Globalmente, foi o género que subiu audiências em mais canais, reforçando a preferência do público português pelo género informativo em televisão (Cardoso et al., 2017, p. 35). Não obstante a televisão continuar a ser o principal recurso para consumo de notícias, as redes sociais têm surgido como a "segunda plataforma noticiosa" mais importante em termos gerais, revelando a expressividade das mudanças operadas pelo digital (Gonçalves, 2015, p.26) principalmente entre as faixas etárias mais jovens. As evidências apontam para a existência de fortes disparidades geracionais nas práticas de consumo, com as gerações mais velhas a privilegiarem assistir televisão na sala de estar, por oposição às gerações mais jovens que, mesmo mantendo uma afinidade muito elevada com a televisão, diversificam os locais de acesso a conteúdos audiovisuais bem como os dispositivos (Burnay \& Ribeiro, 2016, p. 10).

Por outro lado, tem sido possível traçar certas tendências que indicam uma diminuição, de modo geral, do interesse dos jovens por notícias, com acessos cada vez mais pontuais e por breves períodos de tempo, a privilegiarem assuntos sobre entretenimento, celebridades, desporto, moda, ciência e tecnologia, enquanto os assuntos menos acedidos pelos jovens se referem a questões políticas e económicas. Reconhece-se como necessária a investigação centrada nesta questão e na promoção e construção de valores e identidades que permitam aos jovens "um maior sentido de pertença e participação na vida cívica” (Merlo \& Pereira, 2016, p. 95). 


\section{A RELEVÂNCIA DO SERVIÇO PÚBLICO DE TELEVISÃo}

Embora o conceito de televisão pública tenha uma longa história na Europa, continua a ser um fenómeno de difícil descrição em termos simples e não ambíguos, uma vez que o leque de respostas possíveis é, desde logo, restringido por um clima ideológico que contrapõe o favorecimento da regulação do mercado, com visões mais tradicionais de política cultural, destinadas a proteger e defender a radiodifusão pública.

Pode dizer-se, no entanto, que este serviço representa um modelo específico de gestão de media, que prevê um conjunto de intervenções políticas no mercado mediático, ao nível dos apoios, do inventário de obrigações e das estruturas de controlo, com o objetivo de assegurar que os organismos de radiodifusão públicos produzem conteúdos de valor para a sociedade. Historicamente as características que definem estes conteúdos são: a) Cobertura universal; b) Diversidade e qualidade da programação, incluindo satisfação das necessidades dos cidadãos, orientação para objetivos de natureza cultural, atenção a minorias e a grupos específicos, pluralismo e imparcialidade da informação; c) Proteção da cultura e da identidade nacionais, com uma programação que contemple a arte e a cultura, encarando os públicos mais na qualidade de cidadãos do que na de consumidores (Brandão, 2010; Serrano, 2010, p.6; Syvertsen, 2003, p. 157).

O debate quanto à utilidade do modelo de serviço público de radiodifusão implica diversos argumentos e níveis de complexidade (que não seria possível analisar em profundidade neste artigo), a que vêm juntar-se as mudanças introduzidas pela convergência tecnológica e económica. São apontadas vulnerabilidades ao serviço público relacionadas com o facto de os conteúdos, “on demand", poderem ser disponibilizados através de qualquer plataforma o que vem desafiar o seu estatuto de regime especial e limites regulatórios, questionando os apoios públicos e o pagamento de impostos por conteúdos sujeitos a regras que pretendem assegurar a sua qualidade, mas que não atraem grandes audiências (Serrano, 2010, p. 15).

Ao longo da história e apesar das críticas ferozes ao serviço público de televisão, que têm introduzido alterações nos modelos com tendência a erradicar a tradicional distinção entre televisão "pública" e "comercial", a capacidade das instituições e dos decisores políticos para se adaptarem a novas realidades tem sido crucial para a sobrevivência continuada de um sistema regulado publicamente (Syvertsen, 2003, p. 159). 
Entre os argumentos que justificam o modelo de serviço público encontram-se as visões relacionadas com questões de cidadania e de participação, fundamentais para este trabalho. Se a radiodifusão for considerada um bem público devido às suas características de não-exclusão e de não-rivalidade, perante a transmissão de conteúdos populares pelos media privados, o fornecimento de conteúdos educativos, informativos ou de entretenimento de qualidade é altamente desejável e deve ser garantido pelos media públicos (Brandão, 2010; Pinto, 2005; Santos, 2013, pp. 138-139; Trappel et al., 2011).

Para se diferenciar como realidade específica a televisão de serviço público tem de se assumir como "instituição da sociedade, agindo em estreita relação com as outras instituições, vocacionada para lhes dar vez e voz, sem estar condicionada pelas exigências do sucesso, embora também não as enjeitando" (Pinto, 2005, p. 15). No entanto, a exigência deste posicionamento coloca este serviço perante um dilema sem soluções fáceis, sendo que, no futuro, o desafio para os radiodifusores regulados publicamente será convencerem as autoridades políticas que representam uma alternativa valiosa à radiodifusão comercial, com conteúdos de qualidade e na aposta da capacitação informativa e democrática dos cidadãos, ao mesmo tempo que apresentam resultados suficientemente amplos e populares para atrair audiências (Syvertsen, 2003, p. 170).

Apesar de os media serem determinantes na conceção democrática da sociedade, a sua evolução recente não tem sido no sentido de tornar os cidadãos mais conscientes e críticos dos problemas que os rodeiam, no sentido em que a crescente competitividade da oferta subjacente ao desenvolvimento tecnológico e os seus impactos nas práticas jornalísticas, não têm necessariamente bons resultados culturais, cívicos ou mesmo qualitativos. Argumenta-se que, se a finalidade central de qualquer operador privado é o lucro, a sua prioridade não pode ser a de alargar os horizontes das pessoas, integrando em simultâneo as componentes de inovação e de risco económico que isso representa, e que é aqui que o serviço público, enquanto investimento para além dos valores do mercado, continua a encontrar justificação (Santos, 2013, p. 145146).

Com as fronteiras entre "o jornalismo e as formas confessadamente persuasivas do discurso mediático" cada vez mais diluídas, (Brandão, 2010, p.164), as "teorias da conspiração" ligadas à perceção de exclusão do poder político (Moore, 2017) a minar a deliberação democrática e a promover o "ciclo vicioso de cinismo" (Einstein \& Glick, 2013) e a denominada crise de desinformação, que representa o outro 
lado das sociedades digitais, com informações adulteradas a perturbar os processos eleitorais (Conspiracy \& Democracy Project, 2018), o serviço público encontrará as motivações para se reinventar talvez até com maior consistência do que nas últimas duas décadas.

Partimos para a análise da representação do conceito de ativismo na emissora de serviço público de televisão em Portugal, assumindo a convicção de que os media devem comtemplar, no caso dos privados, e privilegiar, no caso do público, a defesa dos interesses fundamentais dos cidadãos, em torno da noção de interesse público, enquanto interesse coletivo de uma sociedade quanto ao aperfeiçoamento do seu conhecimento e constituição cívica (Garcia, 1995, p. 367). Nesta ótica, a transferência de temas que habitam o dinâmico fluxo comunicativo do ambiente digital contemporâneo, onde a ação ativista encontra cada vez mais eco, para o serviço público de televisão, pode contribuir, por um lado, para inverter práticas e representações que tendem a ignorar a agenda dos movimentos ativistas (Hackett, 2000, p. 62), estimulando alguns grupos minoritários a alcançar a massa crítica necessária para obter determinadas mudanças sociais e, por outro, para investigar a veracidade daquilo que é considerado informação no ambiente online.

\section{METODOLOGIA DO ESTUDO}

Foram identificados para este estudo todos os programas de informação transmitidos nos dois canais de televisão de serviço público portugueses - RTP1 e RTP2 que utilizaram as palavras "ativismo" e "ativistas" no ano de $2017^{1}$. Ou seja, a presente análise incide sobre as peças que os próprios jornalistas identificaram como sendo sobre ativismo e ativistas, tendo usado estes termos especificamente na apresentação/ relato das notícias. Para a escolha destes canais tivemos em consideração o facto de serem transmitidos em sinal aberto, sendo, dentro do universo do operador público, os que atingem um maior número de espectadores, segundo dados da audiometria CAEM / GFK. Na verdade, uma parte significativa da população considera que os canais de televisão generalistas oferecem "programas suficientes para a satisfação de suas necessidades informativas e recreativas" (Burnay \& Ribeiro, 2016, p. 25). Ao analisarmos as notícias transmitidas na RTP1 e na RTP2 pretendemos responder às seguintes questões de investigação:

1 Este levantamento foi realizado com apoio da Cision. 
A representação do conceito de ativismo nos programas de informação dos canais de serviço público de televisão em Portugal

- Quantas vezes os programas de informação dos canais públicos de televisão portugueses (RTP1 e RTP2) referiram os conceitos de "ativismo" e de "ativistas" em 2017 ?

- Que causas, movimentos e representações são associadas ao conceito de ativismo nos programas de informação dos canais públicos de televisão (RTP1 e RTP2) em Portugal?

Para a análise de conteúdo foi realizada uma seleção das dimensões sobre as quais a pesquisa pretende incidir, tendo sido criadas uma série de variáveis que serviram de estrutura à análise categorial temática do conteúdo destas peças. O estudo empírico realizado por investigadores da Universidade de Amesterdão (Arbaoui, Swert, \& der Brug, 2016), que efetuou uma análise de conteúdo a uma amostra de 29 noticiários diários em emissoras de televisão públicas e privadas de 14 sistemas de televisão, e a investigação de Nuno Goulart Brandão (2006, p. 151) aos noticiários televisivos portugueses representativos do ano de 2003 foram a base de sustentação metodológica deste trabalho, adaptada ao presente estudo, no que respeita à categorização de dados.

\section{VARIÁVEIS DA ANÁLISE DE CONTEÚDO - QUANTITATIVAS}

Variável 1 - Notícias - Esta variável analisa o número de notícias dos programas de informação dos dois canais generalistas portugueses de sinal aberto do serviço público de televisão português - RTP1 e RTP2 - que em 2017 referiram as palavras "ativismo" e "ativistas".

Variável 2 - Canal - Esta variável examina o número de notícias publicadas por cada canal - RTP1 e RTP2.

Variável 3 - Programa - Esta variável analisa o número de notícias emitidas em cada programa de informação que os canais públicos apresentam nas suas grelhas de programação como informativos de âmbito nacional: Bom Dia Portugal (de Segunda a Sexta-Feira); Jornal da Tarde (diariamente); Portugal em Direto (de Segunda a Sexta-Feira); Telejornal (diariamente); Sexta às 9 (Sexta-Feira); Jornal 2 (diariamente).

Variável 4 - Repetições - Esta variável analisa o número de vezes que cada notícia é repetida. 


\section{VARIÁVEIS DA ANÁLISE DE CONTEÚDO - QUALITATIVAS}

Variável 5 - Duração da Notícia - Esta variável analisa as durações e variações temporais das peças televisivas/notícias objeto de estudo.

Variável 6 - Posicionamento - Esta variável refere-se à localização que a notícia ocupa na ordem de emissão do programa de informação, à semelhança do que Brandão (2006, p. 158) realizou para a análise dos noticiários, numa lógica que permitirá aferir a relevância que o meio de comunicação em causa atribuiu à notícia, sendo que a notícia de abertura destaca os acontecimentos considerados mais relevantes no alinhamento da informação. No caso das notícias de televisão será analisado se a notícia se encontra no início, meio ou fim do programa em causa. No que respeita às características das notícias nos alinhamentos dos programas informativos, são privilegiados "os acontecimentos extraordinários sobre os ordinários, os excecionais sobre os quotidianos, os exclusivos sobre os comuns (...) de modo a que a audiência os possa valorizar" (Brandão, 2010, p. 96). Apesar da duração dos diferentes programas informativos apresentar variabilidades, não sendo consensuais as visões sobre os tempos atribuídos às temáticas dominantes, foram contabilizadas como fazendo parte do início, ou período de tempo até ao fecho da primeira parte dos programas, as peças que foram transmitidas nos primeiros 15 minutos. Foram contabilizadas como estando posicionadas no fim, ou no fecho do programa, as peças que foram transmitidas nos últimos 15 minutos e as restantes foram classificadas como estando no meio do programa.

Variável 7 - Sensacionalismo imagem audiovisual - Não foi analisada a presença de marcas de sensacionalismo na escrita por se entender que, a aplicação de todos os critérios definidos pelos autores do estudo "Sensacionalismo na cobertura de notícias: um estudo comparativo em 14 sistemas de televisão" (Arbaoui, et all., 2016) ao presente estudo poderia enviesar os resultados. Os autores construíram uma variável que indica tópicos de notícias sensacionalistas versus tópicos de notícias não sensacionalistas, de acordo com os seguintes critérios: As peças cuja história central foque temas como crime, corrupção, má conduta, violência, desastres, acidentes, terrorismo, sexo, drogas ou celebridades, serão consideradas sensacionalistas. Da mesma forma, sempre que o sujeito ou sujeitos atores das notícias, aquele ou aqueles sobre os quais recai a atenção central da história, forem cidadãos "comuns" (espectadores, testemunhas, vítimas e perpetradores) são definidos como itens de notícias sensacionais. Tratando a presente análise de peças de televisão que versam sobre questões 
A representação do conceito de ativismo nos programas de informação dos canais de serviço público de televisão em Portugal

de protesto social, a probabilidade de todas a peças analisadas fazerem referência a estes temas seria elevada, sendo arriscado assumir que todas as peças que fazem referência a estes temas são sensacionalistas. Por este motivo e para não se aprofundar a discussão sobre o que são, ou não, conteúdos escritos sensacionalistas, uma vez que que não representa o foco direto do trabalho, a opção metodológica recaiu na análise de características mais evidentes relacionadas com a imagem audiovisual de acordo com os critérios definidos pelos autores do estudo referenciado enquanto suporte metodológico (Arbaoui et al., 2016, p. 8-9). Serão avaliadas nas peças de televisão características que estimulam o sistema sensorial humano como o uso de música de fundo na notícia; o uso de efeitos especiais em imagens (movimento lento, aceleração de movimento, repetição de efeitos visuais, close-ups, foco suave); e o uso de representação pictórica ou gráfica que não seja um auxiliar da notícia exclusivamente informativo (Arbaoui et al., 2016, p. 8-9). Esta variável apura se as notícias em análise integram os elementos sensacionalistas do ponto de vista da imagem audiovisual e tem duas possibilidades de categorização: $\operatorname{sim}$ ou não.

Variável 8 - Causas - Esta variável identifica o tipo de causas defendidas nas peças de televisão em análise: Direitos humanos - Nesta categoria enquadram-se todas as peças que refiram a defesa dos direitos que constam na Declaração Universal dos Direitos Humanos adotada pela Organização das Nações Unidas em 10 de dezembro de 1948; Direitos ambientais/da Natureza - Nesta categoria são identificadas todas as notícias que se refiram aos direitos da natureza e à ética de proteção ambiental (Cullinan, 2011; Klein, 2014; Nash, 1989); Direitos dos animais - Nesta categoria enquadram-se todas as notícias que se refiram à proteção dos animais não humanos (Cavalieri, 2002; Singer, 2009). Sempre que as reivindicações ativistas apresentadas nas peças de televisão em análise não se refiram especificamente a nenhuma destas causas, a peça em questão será categorizada especificando o tipo de ação ativista em questão.

Variável 9 - Tipo de Atores/Organizações ativistas - Nesta categoria são agrupados os atores sociais presentes nas peças de televisão de acordo com o nível de organização e pode ter três opções de categorização: No nível micro - indivíduos ativistas que podem integrar redes de protesto ativadas pela multidão não estando ligados a nenhum tipo de organização de movimento social. No nível meso - estão os atores coletivos na organização das mobilizações, ou seja, formações coletivas em que alguns indivíduos se juntam para interagir numa base estável. No nível macrossocial - é possível agrupar os atores do movimento social coletivo de acordo com sua cultura 
política, públicos-alvo, causas, objetivos e capacidade de influenciar mobilizações (Mattoni \& Treré, 2014, pp. 256-257). Em cada um destes níveis serão também identificados os nomes das organizações ativistas. Sempre que a referência aos conceitos "ativismo" ou "ativistas" surja noutro contexto, como a referência indireta a ação ativista não relacionada com nenhuma ação proativa específica por parte de ativistas, organizados ou não, a peça será categorizada como Não se Aplica (NA).

Variável 10 - Tratamento Geográfico - Esta variável possibilita categorizar as notícias "predominantes no plano nacional e quais são as do plano internacional" (Brandão, 2006, p.157).

Variável 11 - Tom/Valência - Esta variável avalia "se a notícia contém uma valorização neutra, sentido positivo ou negativo em relação à ação dos ativistas, ou seja, correspondentes às chamadas: «notícias neutras», «notícias boas» ou «notícias más» " (Brandão, 2006, p.158).

Variável 12 - Título/Tema - Esta variável identifica o assunto da notícia. Tratando-se de notícias televisivas que não têm um título propriamente dito, identifica a temática concreta relatada na peça de televisão, recorrendo a abertura/introdução do tema ou á informação presente nas notas de rodapé, nos casos em que existam.

Variável 13 - Porta-vozes das causas ativistas - Esta variável identifica quem são os porta-vozes que explicam o que está em causa e quais as suas as reivindicações. As opções de categorização são: cidadão comum; especialista de fora da organização, especialista da organização; Porta-voz da organização (institucional); figura pública ou Outro (voz off do jornalista na narração dos acontecimentos). A mesma peça de televisão pode incluir Porta-vozes em mais do que uma categoria.

Variável 14 - Tipo de Ação ativista - A análise desta variável pretende apurar qual o tipo de ação ativista que prevalece nas notícias em análise e tem as seguintes possibilidades de categorização: Métodos de protesto e persuasão - que vão além do comportamento convencional, como discursos, slogans, cartazes, protestos, vigílias, cantos, marchas e palestras; não-cooperação - desobediência aos costumes sociais, denúncia, emigração de protesto, boicote dos produtores, retiro de depósitos bancários, embargo comercial internacional e uma ampla variedade de greves; intervenção - ocupações não-violentas, teatro de guerrilha, jejum e a criação de instituições económicas e políticas alternativas (Sharp, 2005, p. 25-30); violência contra objetos físicos e ação violenta - Luta armada (Martin, 2007, p. 21).

Variável 15 - Confrontos - Esta variável analisa se as notícias de televisão que referem os conceitos de "ativismo" e de "ativistas" relatam e/ou mostram imagens de confrontos físicos/violência entre polícia/autoridades e manifestantes/ativistas. 
A representação do conceito de ativismo nos programas de informação dos canais de serviço público de televisão em Portugal

Variável 16 - Perfil - Analisa se a peça em causa se refere aos ativistas enquanto vítimas, agressores ou é neutra em relação a este critério.

Variável 17 - Online - Esta variável analisa se a notícia de TV faz referência a fontes de informação que tenham tido origem ou se tenham desenvolvido no ambiente digital, Redes Sociais, Sites, Blogues ou outros (devidamente identificados).

\section{ANÁLISE DE RESULTADOS}

O primeiro objetivo foi quantificar quantas vezes os programas informativos dos canais RTP1 e RTP2 referiram os conceitos de "ativismo" e de "ativistas" em 2017, tendo sido obtidos os seguintes resultados:

Tabela 1

Transmissão de programas dos canais públicos generalistas portugueses com e sem referência aos conceitos de "ativistas" e "ativismo" em 2017.

\begin{tabular}{lccc}
\hline Programa/Canal & No Emissões 2017 & $\begin{array}{c}\text { No programas } \\
\text { sem ref/At. }\end{array}$ & $\begin{array}{c}\text { \% programas } \\
\text { com ref/At. }\end{array}$ \\
\hline Bom Dia Portugal (RTP1) & 250 & 195 & $22 \%$ \\
Jornal da Tarde (RTP1) & 365 & 340 & $6,80 \%$ \\
Telejornal (RTP1) & 365 & 340 & $6,80 \%$ \\
Sexta às 9 (RTP1) & 52 & 51 & $1,90 \%$ \\
Jornal 2 (RTP2) & 365 & 350 & $4,10 \%$ \\
\hline
\end{tabular}

Os programas acima identificados dos canais públicos de televisão portugueses (RTP1 e RTP2) referiram os conceitos de "ativismo" e de "ativistas" 120 vezes em 2017, sendo que na RTP1 os conceitos foram referidos 106 vezes e na RTP2 foram contabilizadas 15 referências. O programa de informação matinal da RTP1 - Bom Dia Portugal - foi o que referiu mais vezes estes conceitos (55), sendo que apesar disso, do total de programas emitidos no ano de 2017 (250), 22\% referiram as palavras "ativistas" ou "ativismo". Do total de peças analisadas 43 foram originais e 77 foram repetidas pelos diferentes programas o que reduz o número total real de "histórias" com referência a estes conceitos. A duração das notícias varia entre os 23 segundos (mais curta) e os dois minutos e 41 (mais longa), sendo que a maioria (87) se encontra no meio dos programas informativos, 24 no início, e nove no fim. No que 
respeita à variável sensacionalismo na imagem audiovisual nenhuma das notícias analisadas revelou estes indicadores, mesmo nas situações em que são mostrados cenários de conflitos e confrontos. As imagens refletem apenas os acontecimentos e não revelam tratamento adicional que as possa qualificar de sensacionalistas de acordo com os critérios definidos. No que respeita às causas defendidas, como demonstra a Figura 1, os Direitos Humanos foram a área que obteve maior número de referências nas notícias (57) seguida de referências a formas de ativismo político (31), ou seja, de protestos contra situações e escolhas políticas concretas como a situação do independentismo na Catalunha e escândalos de corrupção. Seguem-se os direitos do ambiente (19) e as peças em que era defendida mais do que uma causa, as peças que fizeram referência aos direitos dos animais foram cinco.

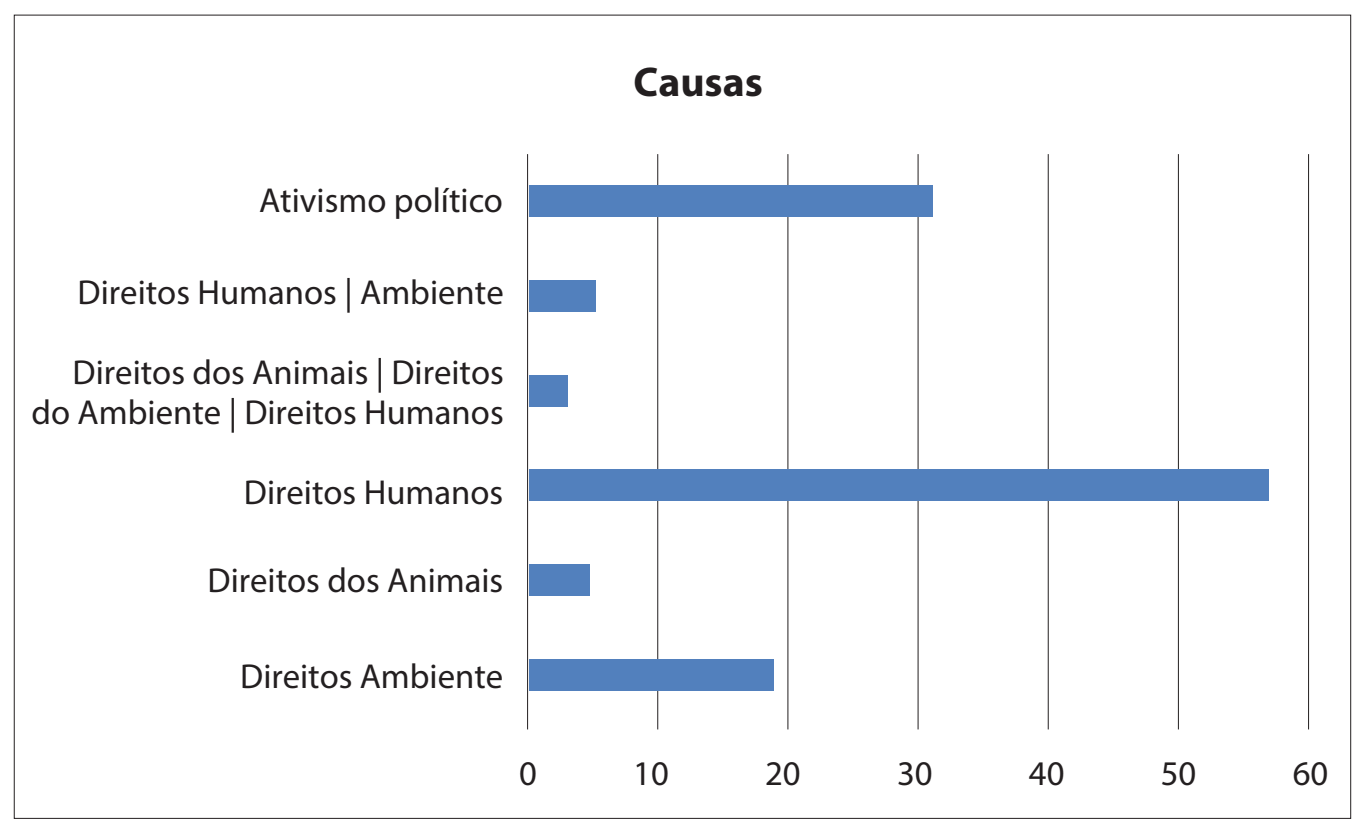

Figura 1. Tipo de causas defendidas nas peças de televisão em análise

No que respeita ao Tipo de Atores/Organizações ativistas, tal como demonstra a Figura 2, foi ao nível micro, com $41 \%$ das peças de televisão analisadas, que se detetaram mais referências. A este nível estamos a falar de indivíduos ativistas que integram redes de protesto não estando ligados a nenhum tipo de organização de movimento social. Cruzando esta variável com a variável tratamento geográfico é possível obser- 
A representação do conceito de ativismo nos programas de informação dos canais de serviço público de televisão em Portugal

var que apenas quatro destas peças são de âmbito nacional, ou seja, das 49 peças que referem formas de ativismo não organizado, a grande maioria é de âmbito internacional. Das peças analisadas 31 referiam-se ao nível meso de organização, formações coletivas em que alguns indivíduos se juntam para interagir numa base estável e a este nível 13 das peças são de âmbito nacional. Já no nível macro, aquele em que é possível agrupar os atores do movimento social coletivo de acordo com sua cultura política, públicos-alvo, causas, objetivos e capacidade de influenciar mobilizações foram analisadas 37 peças, sendo que a este nível as referências de âmbito nacional aumentam significativamente, com apenas 7 peças de âmbito internacional, o que poderá ser um indicador de que é atribuída maior atenção mediática televisiva a iniciativas ativistas que resultem de movimentos organizados no tempo e no espaço. Ainda no nível macro foi possível identificar as seguintes organizações referidas nas notícias sobre ativistas e ativismo nos canais de televisão pública portuguesa em 2017: Amnistia Internacional (AI); Black Lives Matter; Campanha Linha Vermelha; Conselho Nacional dos Ativistas de Angola; Grupo de Ativistas em Tratamento (GAT); Greenpeace; Movimento Pró Tejo; Plataforma Espanhola de Toledo; Quercus; National Geographic; Zero.

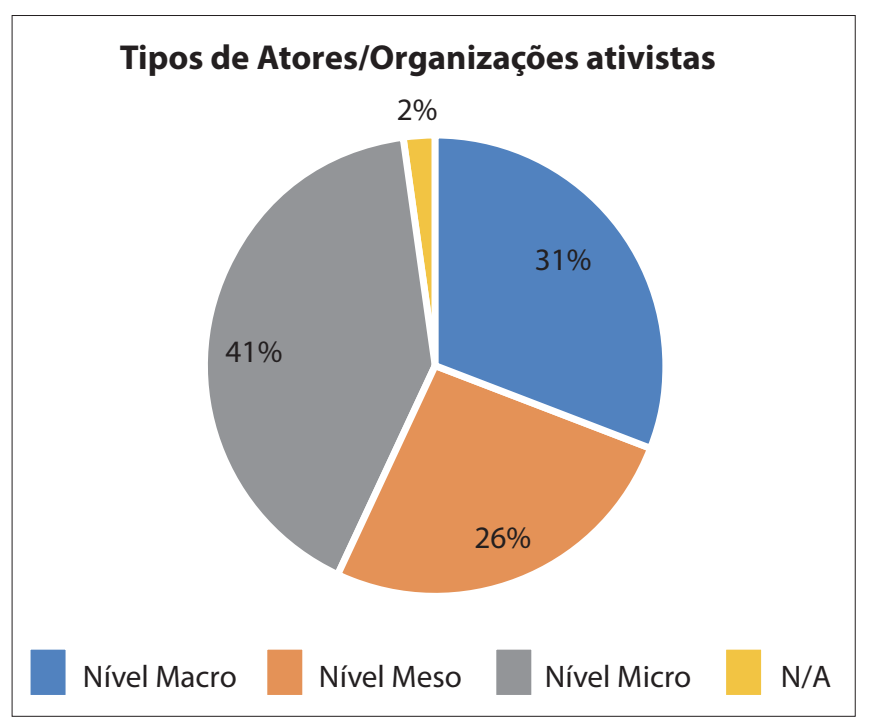

Figura 2. Tipo de Atores/Organizações ativistas representados nas peças de televisão em análise 
No que respeita ao tratamento geográfico de destacar que a maioria das referências é de âmbito internacional (82) sendo que apenas 38 notícias se referem a iniciativas ativistas de âmbito nacional. Já a análise da variável Tom/Valência indica que as associações feitas aos ativistas presentes nas peças de televisão, nomeadamente através da voz off ou da locução, são maioritariamente positivas (94), o que sugere que a televisão apresenta, neste contexto, o modelo de jornalismo de "cão de guarda" que supervisiona as atividades das autoridades públicas em nome dos cidadãos (Dyck \& Zingales, 2002; Serrin \& Serrin, 2002), com 17 peças a apresentarem uma abordagem puramente neutra e apenas 9 das peças analisadas a apresentarem um tom negativo relatando confrontos com as autoridades ou com outros grupos ativistas e vandalização de monumentos. Os assuntos das notícias analisadas são apresentados na Tabela 2 com destaque para o processo independentista catalão com maior número de peças repetidas, seguido de manifestações contra cortes e falhas nos tratamentos da Hepatite A, de protestos contras as políticas de Donald Trump e manifestações contra a Guerra na Síria.

Tabela 2

Título/tema das notícias e respetivas repetições nos programas e notícias em estudo

\begin{tabular}{lc}
\multicolumn{1}{c}{ Tema/Título } & No Notícias \\
\hline Tensão na Catalunha & 14 \\
Hepatite A - cortes e falhas nos tratamentos & 12 \\
Manifestações contra Donald Trump & 8 \\
Guerra na Síria & 8 \\
Detenções Membros AI na Turquia & 7 \\
Situação política em Luanda & 7 \\
Alterações climáticas em debate & 6 \\
Anti Energia Nuclear - Central de Almaraz & 6 \\
Direitos Humanos - China & 6 \\
Apoio a refugiados & 5 \\
Começou o Brexit & 4 \\
Manifestações em Israel & 3 \\
Manifestação anti racismo - Boston & 3 \\
Dia Mundial de Luta contra a Sida & 3 \\
\hline
\end{tabular}


A representação do conceito de ativismo nos programas de informação dos canais de serviço público de televisão em Portugal

Tabela 2 (continuação)

$$
\text { Tema/Título }
$$

No Notícias

Tensão na Venezuela - Protestos contra Maduro

Protesto contra os níveis de poluição no rio Tejo

Eleições presidenciais francesas

Ativistas National Geographic em Lisboa

Violência em Itália - Reunião G7

Relatório da Amnistia Internacional

Encontro da Mesa Nacional do Bloco de Esquerda

Fim do circo "O maior espetáculo da terra"

Gaia Todo o Mundo - Fórum Internacional

Protesto da extrema-direita na Virgínia - Contra Protesto pacifista

Atentado em Barcelona - Estado Islâmico

Conflitos Ameaça Nuclear Coreia do Sul - Coreia do Norte

Polémica em Tóquio c/ sem abrigo - Jogos Olímpicos 2020

Ativistas da Greenpeace colocaram uma faixa na Torre Eiffel

Conferências do Estoril

Copenhaga - Estátua da "Pequena Sereia" vandalizada

Festival Lisboa Mistura - arte interventiva

Protestos na Argentina

Incêndios e a seca o pior de 2017

2 anos de "geringonça" 1

Protesto em Sines - contra furos petróleo em Portugal 1

A identificação dos porta-vozes das causas ativistas (Figura 3) revela que, nas notícias de televisão em análise, o cidadão comum é o porta-voz privilegiado (41), seguido de peças apenas com locução do jornalista (26). As peças que apresentam um porta-voz institucional da organização ou do movimento ativista, mesmo não sendo considerado um especialista numa área específica, são 24. 


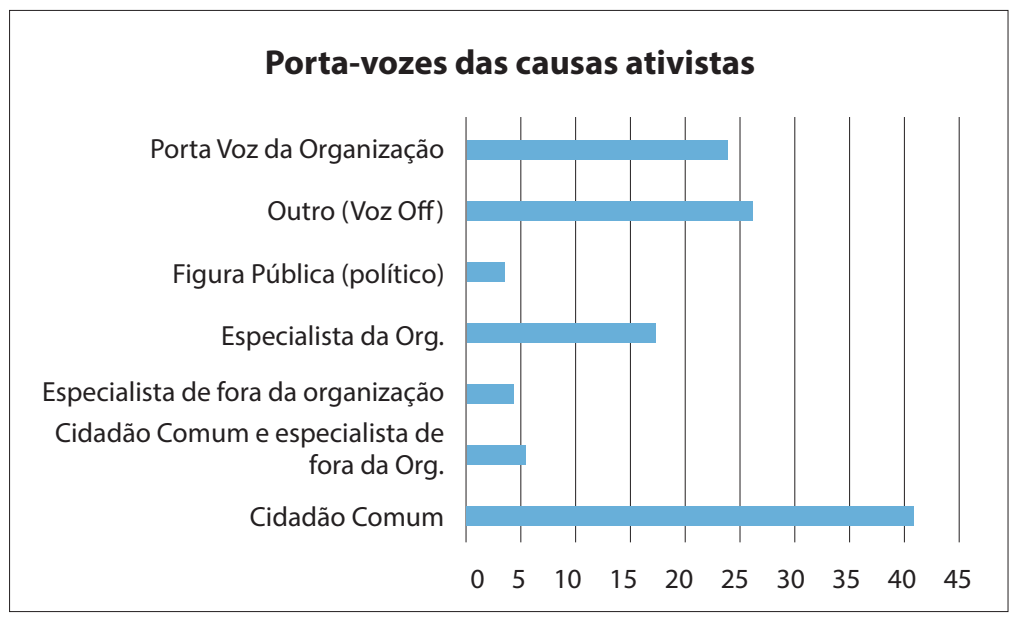

Figura 3. Porta-vozes das causas ativistas representados nas peças de televisão em análise

O tipo de ação ativista (Figura 4) que prevalece nas notícias em análise (95\%) é claramente o protesto e a persuasão com iniciativas concretas que envolvem presença física dos intervenientes e ações de rua (manifestações; conferências; campanhas específicas; denúncia de abusos) seguido da violência contra objetos físicos ou ação violenta (3\%) e da não cooperação (2\%).

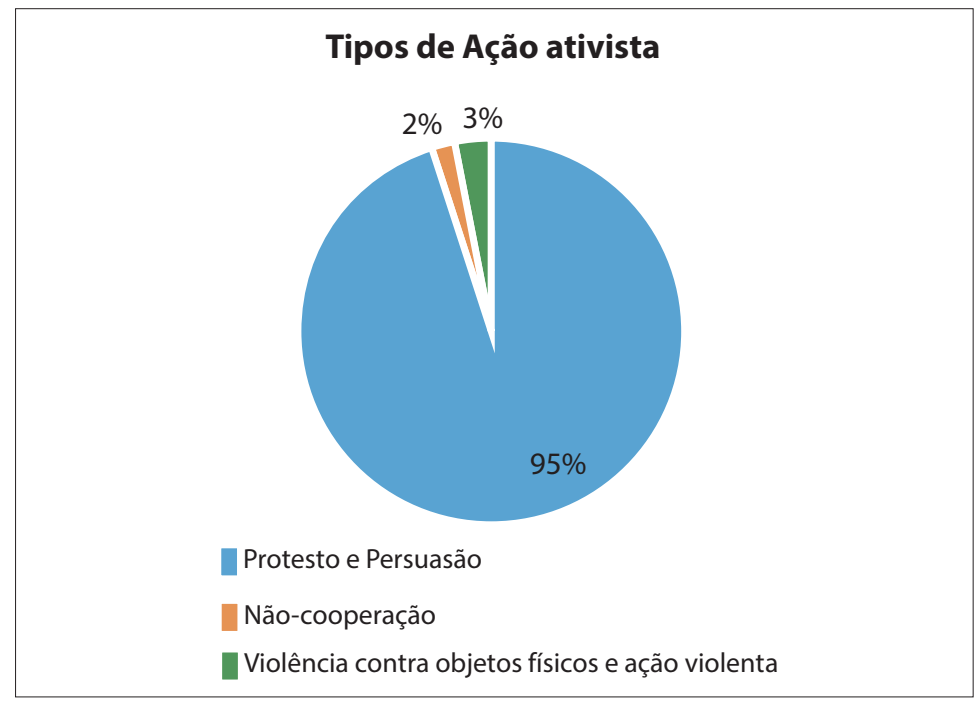

Figura 4. Tipo de ação ativista nas peças de televisão em análise 
A grande maioria das peças analisadas não mostra imagens de confrontos físicos/ violência entre polícia/autoridades e manifestantes/ativistas conforme se pode observar na Figura 5:

\section{Confrontos}

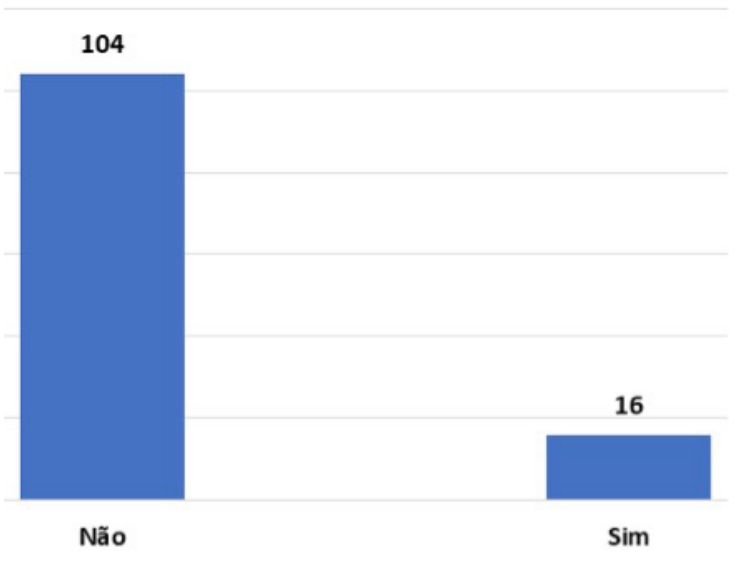

Figura 5. Confrontos nas peças de televisão em análise.

De acordo com um estudo que analisou os canais do YouTube de duas comunidades feministas virtuais que lidam com a violência contra a mulher, os signos das mensagens audiovisuais são complexos e recorrem a artefactos semióticos que produzem significado, estando sempre envolvidos numa representação que se destina a procurar compreender os valores e as posições dos envolvidos num determinado fenómeno, sendo que a variação do termo "vítima" ou "agressor" foi analisada, no presente estudo, dentro dos limites discursivos impostos ao jornalismo no que respeita às noções de objetividade e de imparcialidade (Núñez, Fernández, \& Rubira, 2015). Posto isto, a grande maioria das peças analisadas é neutra em relação ao perfil dos ativistas (102), sendo que 16 das peças, em contextos de violações evidentes dos direitos humanos fundamentais, apresentam os ativistas como vítimas e apenas duas relacionadas com uma explosão na Colômbia provocada por um grupo ativista anti tourada os apresentam como agressores. Na variável online, das 120 notícias analisadas apenas uma, sobre um protesto promovido pela Amnistia Internacional contra o retrocesso das políticas de Donald Trump na área ambiental, fez referência ao ambiente digital, concretamente à página de Facebook da AI. 


\section{DISCUSSÃO DE RESULTADOS}

Estudar o conceito de ativismo apresenta uma série de limitações pela própria subjetividade do que implica, muito sujeito a interferências conjunturais relacionadas com a localização geopolítica, o contexto espácio-temporal e cultural em que as iniciativas associadas ao conceito se desenvolvem e também aos automatismos psicológicos e sociobiológicos dos indivíduos (Núñez et al., 2015). A presente análise reflete estas limitações na medida que os acontecimentos que geram notícias de televisão associadas aos conceitos de "ativismo" e de "ativistas" são também conjunturais, por um lado, e, por outro lado, podem existir relatos associados a ações e organizações ativistas que, não tendo sido referidos pelos jornalistas especificamente como tal, tenham ficado fora do âmbito da análise, ou seja, é possível existirem peças que os jornalistas identificariam como sendo sobre ativismo mesmo sem usar essas palavras. Por outro lado, as opções metodológicas subjacentes ao critério de seleção das peças de televisão para análise excluem outras variantes de expressões relacionadas com o objeto de estudo, como o termo "ativista" no singular, por se ter privilegiado a variante de ação social coletiva. De igual forma, será interessante, no futuro, fazer a comparação da cobertura destes temas e programas entre os canais públicos e os privados, alargando substancialmente a amostra, aprofundando o cruzamento dos dados obtidos em algumas dimensões e analisar tendências ao longo do tempo.

No entanto, foi possível responder às questões de investigação colocadas e quantificar e identificar que causas, movimentos e representações são associadas a estes conceitos nos programas informativos da televisão pública portuguesa. A análise revelou-se elucidativa no que respeita aos assuntos cobertos, às causas com maior representatividade que são de âmbito internacional e relacionadas fundamentalmente com questões políticas e de direitos humanos. Sendo práticas sociais dotadas de uma grande mutabilidade, as ações ativistas são também alvo de uma volátil projeção mediática (Estanque \& Bebiano, 2007), no entanto, foi possível observar que os programas informativos da RTP1 e da RTP2 não destacam a ação dos grupos ativistas que praticaram atos violentos, nem revelam indícios de cobertura audiovisual sensacionalista. Por outro lado, são privilegiadas as ações concretas no terreno, cujos porta-vozes são os cidadãos comuns ao nível micro. Esta inclinação na análise pode refletir uma tendência do sistema mediático para o aumento progressivo da interação e identificação com as audiências (Brandão, 2010, p. 95). Quando comparado com o 
total de emissões de cada programa informativo dos dois canais de serviço público em 2017, o número de programas que referiu os conceitos de "ativismo" e "ativistas" é reduzido. O programa de informação matinal da RTP 1 - Bom Dia Portugal - foi o que referiu mais vezes estes conceitos (52), sendo que apesar disso, do total de programas emitidos no ano de 2017 (250), apenas 22\% referiram estas expressões. De uma forma geral a maioria das peças tem duração inferior a um minuto (115), sendo que as peças mais longas, acima de dois minutos (5), dizem respeito a temas como a violação de Direitos Humanos na China, aos Protestos contra Donald Trump e ao Debate sobre Energia Nuclear - Central de Almaraz.

As peças em análise surgem colocadas principalmente no meio dos programas informativos, sem grande destaque, com a maior parte das notícias a serem repetições de assuntos de âmbito internacional, podendo ser indicadores de que, por um lado, no contexto nacional a ação ativista não é musculada o suficiente para atrair atenção mediática televisiva, ou por outro, que o serviço público de televisão desvaloriza a cobertura de ações ativistas como um elemento fundamental da formação da cidadania, reconhecendo, no entanto, que os resultados apresentados estão distantes de ser conclusivos em relação a estas hipóteses. De realçar também para estas considerações, o facto de praticamente não haver referência nas peças analisadas a acontecimentos iniciados e propagados no ambiente digital, o que pode sugerir um fosso entre o que mostram os ecrãs televisivos públicos e a forma como determinados tópicos adquirem relevância online.

Uma investigação empírica recente de uma equipa dos Estados Unidos e do Reino Unido, publicada na revista Science, traz novidades sobre as dimensões que os movimentos sociais precisam ter para alcançar mudanças de comportamentos na sociedade. Abordando temas atuais que vão desde o movimento contra o assédio sexual \#MeToo, à propaganda política na China e ao debate sobre o acesso às armas de fogo nos Estados Unidos da América, a teoria desenvolvida sugere que quando um grupo minoritário atinge os $25 \%$ do total de uma população, torna-se capaz de influenciar a aceitação de normas, comportamentos e crenças na sociedade, partindo do princípio de que todos os indivíduos têm os mesmos recursos e poder social. Quando os grupos minoritários alcançaram a massa crítica - isto é, o tamanho do grupo crítico para iniciar a mudança social - eles foram consistentemente capazes de derrubar o comportamento estabelecido (Centola et al., 2018, p. 1116).

Se, como foi visto, em Portugal os vários movimentos se têm revelado incapazes de gerar lideranças que façam com que as revoluções atinjam os níveis de mudança e 
inovação social profundos alcançados por outros países, sendo os meios de comunicação social tradicionais, principalmente a televisão no seu modelo de serviço público, fundamentais para a mudança de hábitos e de mentalidades, será de esperar que, na sua conquista por relevância, se possa posicionar enquanto espaço privilegiado, por excelência, para equilibrar as dinâmicas dos pesos e contrapesos existentes no espaço público, auxiliando determinados grupos ativistas a alcançar a massa crítica necessária para que a mudança social ocorra.

Evidências recentes indicam que os níveis de desconfiança dos cidadãos em relação aos media, bem como a perceção de parcialidade editorial têm vindo a aumentar nos últimos anos na maioria das democracias ocidentais (Ardèvol \& Zúñiga, 2017). Se as tecnologias trouxeram um novo espaço de visibilidade para organizações ativistas solidárias, não violentas e inclusivas, elas também tornaram possível para organizações extremistas e movimentos totalitários criar espaços virtuais que naturalmente minam a confiança pública nas eleições, nos tribunais, nos media tradicionais e na ciência, com teorias da conspiração, falsas narrativas e perspetivas ignorantes sobre religião e raça (Albright, 2018, pp. 20-30). Neste contexto, aqueles que definem e procuram influenciar o que é transmitido nos telejornais, têm maior responsabilidade e interesse em fornecer perspetivas que permitam às audiências uma maior independência das mais variadas tentativas de "subjugação intelectual" inerentes à produção e disseminação de informação (Tornero \& Varis, 2010, pp. 24-26).

\section{REFERENCIAS}

Albright, M. (2018). Fascism: A Warning. New York: HarperCollins.

Arbaoui, B., Swert, K. D., \& Der Brug, W. (2016). Sensationalism in News Coverage: A Comparative Study in 14 Television Systems. Communication Research. doi: $10.1177 / 0093650216663364$

Ardèvol-Abreu, A., \& Gil De Zúñiga, H. (2017). Effects of Editorial Media Bias Perception and Media Trust on the Use of Traditional, Citizen, and Social Media News. Journalism \& Mass Communication Quarterly, 94(3), 703-724. doi: $\underline{10.1177 / 1077699016654684}$ 
A representação do conceito de ativismo nos programas de informação dos canais de serviço público de televisão em Portugal

Assis, É. G. (2006). 'Táticas lúdico-midiáticas no ativismo político contemporâneo' (dissertação de mestrado não publicada). Universidade do Vale do Rio dos Sinos, São Leopoldo.

Baer, H. (2016). Redoing feminism: digital activism, body politics, and neoliberalism", Feminist Media Studies, 16:1, 17-34. doi:10.1080/14680777.2015.1093070

Bandura, A. (2002). Social Cognitive Theory in Cultural Context. Applied Psychology: An International Review 51, 269.

Benhabib, Seyla. (1996). Toward a Deliberative Model of Democratic Legitimacy. In S. Benhabib (Ed.), Democracy and Difference: Contesting the Boundaries of the Political (68-94). Princeton, NJ: Princeton University Press

Benkler, Y. (2006). The Wealth of Networks. New Haven: Yale University Press.

Bennett, W. L., (2014). Communicating Global Activism: Some Strengths and Vulnerabilities of Networked Politics. In Wim van de Donk, Brian D. Loader, Paul G. Nixon, \& Dieter Rucht (Eds.), Cyberprotest: New Media, Citizens and Social Movements. London: Routledge

Bennett, W. L., \& Segerberg, A. (2013). The logic of connective action: Digital media and the personalization of contentious politics. Cambridge: Cambridge University Press.

Bobel, C. (2007). "I'm not an activist, though I've done a lot of it": Doing Activism, Being Activist and the "Perfect Standard" in a Contemporary Movement. Social Movement Studies 6, 147-159.

Brandão, N. G. (2006). Prime Time - do que falam as notícias dos telejornais. Lisboa: Casa das Letras.

Brandão, N. G. (2010). As Notícias nos Telejornais. Lisboa: Guerra \& Paz.

Burnay, C. D., \& Ribeiro, N. (2016). As novas dinâmicas do consumo audiovisual em Portugal. ERC - Entidade Reguladora para a Comunicação Social.

Campos, R., Pereira, I., \& Simões, J. A. (2016). Ativismo digital em Portugal, Um estudo exploratório. Sociologia, problemas e práticas, 82, 27-47. doi:10.7458/ $\underline{\text { SPP2016826977 }}$

Cardoso, G., Costa, A. F., Coelho, A. R., \& Pereira, A. (2015). A Sociedade em Rede em Portugal: Uma Década de Transição. Coimbra: Almedina 
Cardoso, G., Mendonça, S., Paisana, M., Lima, T., \& Caldeira P. P. (2017). A Televisão em Portugal. Análise das audiências e dinâmicas concorrenciais do mercado televisivo português entre 1999 e 2016, Relatórios OberCom - Observatório da Comunicação.

Cardoso, G., Vieira J., \& Mendonça, S. (2016). Ecrãs em Rede - Televisão - Tendências e Prospectivas, Relatórios OberCom - Observatório da Comunicação.

Castells, M. (2017). Redes De Indignação e Esperança: Movimentos Sociais na Era da Internet. Rio de Janeiro: Zahar.

Cavalieri, P. (2002). The Animal Question: Why Non-Human Animals Deserve Human Rights. New York: Oxford University Press.

Centola, D., Becker, J., Brackbill, D., \& Baronchelli, A. (2018, June 8), Experimental evidence for tipping points in social convention. Science, Vol. 360, (6393), 11161119. doi:10.1126/science.aas8827

Corrigall-Brown, C. (2012). Patterns of Protest: Trajectories of Participation in Social Movements. Stanford: Stanford University Press.

Cortese, D. K. (2015, May). I’m a "good" activist, you're a "bad" activist, and everything I do is activism: parsing the different types of "activist" identities in LBGTQ organizing. Interface: a journal for and about social movements, 7 (1), 215-246.

Costa, A. C. (2019). As Cinco Grandes Revoluções da História de Portugal. Lisboa: Desassossego.

Couldry, Nick (2004). Theorising media as practice. Social Semiotics, 14(2), 115-132. doi: $\underline{10.1080 / 1035033042000238295}$

Cullinan, C. (2011). Wild Law - Manifesto For Earth Justice. Totnes: Green Books.

Curran, James (2012). Understanding the Internet. London: Routledge.

Della Porta, D. (2015). Democracy in Social Movements. In D. Della Porta \& M. Diani, The Oxford Handbook of Social Movements. Oxford: Oxford University Press.

Deuze, M. (2011). Media life. Media, Culture \& Society, 33(1), 137-148. doi: $10.1177 / 0163443710386518$ 
A representação do conceito de ativismo nos programas de informação dos canais de serviço público de televisão em Portugal

Dyck, A., \& Zingales, L. (2002). The corporate governance role of the media. In R. Islam (Ed.), The right to tell: The role of mass media in economic development (pp. 101-137). Washington, DC: The World Bank Institute.

Earl, J., \& Kimport, K. (2011). Digitally Enabled Social Change: Activism in the Internet Age. Cambridge, Mass.: MIT Press.

Einstein, K. L., \& Glick, D. M. (2013). 'Scandals, Conspiracies and the Vicious Cycle of Cynicism'. Paper presented at the Annual Meeting of the American Political Science Association.

Estanque, E., \& Bebiano, R. (2007). Do Activismo à Indiferença, Movimentos Estudantis em Coimbra. Lisboa: Imprensa de Ciências Sociais.

Evans, E. (2011). Transmedia Television Audiences, New Media, and Daily Life. New York: Routledge.

Fuchs, C. (2013). Social media: A critical introduction. London: Sage.

Gamson, J. (1995). Must Identity Movements Self-Destruct? A Queer Dilemma. Social Problems, 42(3), 390-407. doi:10.2307/3096854

Garcia, J. L. (1995). Os jornalistas portugueses enquanto actores do espaço público mediatizado. Legitimidade, Poder e Interpretação. Revista de Comunicação e Linguagens, Comunicação e Política. 21-22, 367-368.

Gladwell, M. (2011). From innovation to revolution-do social media made protests possible: An absence of evidence. Foreign Affairs, 90, 153.

Gonçalves, T. (2015). Públicos e consumos de média o consumo de notícias e as plataformas digitais em Portugal e em mais dez países, Entidade Reguladora para a Comunicação Social (ERC).

Hackett, R. (2000). Taking Back The Media: Notes On The Potential, For A Communicative Democracy Movement. Studies in Political Economy 63, (1), 61-86. doi: $\underline{10.1080 / 19187033.2000 .11675233}$

Halupka, M. (2014). Clicktivism: A systematic heuristic. Policy \& Internet, 6, 115132. doi:10.1002/1944-2866.POI355

Jordan, T. (2002). Activism!: Direct Action, Hacktivism and the Future of Society, London: Reaktion Books Ltd. 
Jouët, J. (2018). Digital feminism: questioning the renewal of activism. Journal of Research in Gender Studies 8(1), 133-157.

Joyce, M. C. (2014). 'Activism Success: A Concept Explication'. A thesis submitted in partial fulfillment of the requirements of the degree of Master of Arts, University of Washington.

Karpf, D. (2010). Online political mobilization from the advocacy group's perspective: Looking beyond clicktivism. Policy \& Internet, 2(4), 7-41. doi:10.2202/1944$\underline{2866.1098}$

Kennelly, Jacqueline (2009). Good Citizen/Bad Activist: The Cultural Role of the State in Youth Activism. The Review of Education, Pedagogy, and Cultural Studies, 31:2-3, 127-149. doi:10.1080/10714410902827135

Klein, N. (2002). No Logo - Taking Aim at the Brand Bullies. New York: Picador.

Klein, N. (2014). This Changes Everything. New York: Simon \& Schuster.

Kunsch, M. M. K., \& Kunsch, W. L. (2007). Relações Públicas Comunitárias: A comunicação numa perspetiva dialógica e transformadora. São Paulo: Summus Editorial.

Mackinnon, R. (2011). Liberation Technology: China's "Networked Authoritarianism”. Journal of Democracy 22(2), 32-46. Johns Hopkins University Press. Retrieved June 18, 2019, from Project MUSE database.

Malaspina, C. (2014). 'The Spiral of Silence and Social Media: analyzing Noelle-Neumann's phenomenon application on the Web during the Italian Political Elections of 2013'. Media@LSE, London School of Economics and Political Science.

Martin, B. (2007). Activism, social and political. In Gary L. Anderson and Kathryn G. Herr (Eds.), Encyclopedia of Activism and Social Justice. Thousand Oaks, CA: Sage.

Matthes, J. (2015). Observing the "Spiral" in the Spiral of Silence, International Journal of Public Opinion Research, 27(2), 155-176.

Mattoni, A., \& Treré, E. (2014), Media Practices, Mediation Processes, and Mediatization in the Study of Social Movements. Communication Theory, 24, 252-271. doi: $10.1111 /$ comt.12038 
A representação do conceito de ativismo nos programas de informação dos canais de serviço público de televisão em Portugal

Merlo, A. I., \& Pereira, S. (2016). Os jovens e o acompanhamento da informação sobre a atualidade: questões a partir da análise de Relatórios sobre usos e práticas mediáticas. Observatório $\left(\mathrm{OBS}^{*}\right), 10$ (3), 80-97.

Moore, A. (2017). Conspiracies, Conspiracy Theories and Democracy. Political Studies Review 2018, Vol. 16(1), 2-12.

Morozov, E. (2011). The Net Delusion: The Dark Side of Internet Freedom. Cambridge, MA: Perseus Books.

Nash, R. (1989). The Rights of Nature: A History of Environmental Ethics. Madison: The University of Wisconsin Press.

Noelle-Neumann, E. (1974), The Spiral of Silence a Theory of Public Opinion. Journal of Communication, 24 (2), 43-51.

Núñez P. S., Fernández R. D., \& Rubira García, R. (2015). Online activism and subject construction of the victim of gender-based violence on Spanish YouTube channels: Multimodal analysis and performativity. European Journal of Women's Studies, 22(3), 319-333. doi:10.1177/1350506814567002

Pinto, M. (2005), Televisão e Cidadania: Contributos para o debate sobre o serviço público. Porto: Campo das Letras.

PwC (2019). PwC's Global Entertainment \& Media Outlook 2019-2023. Retrieved from https://www.pwc.com/gx/en/industries/tmt/media/outlook.html

Ribeiro, N. (2015). The Discourse on New Media: Between Utopia and Disruption. In S. Kinnebrock, C. Schwarzenegger, T. Birkner (Eds.), Theorien des Medienwandels. Köln: Herbert von Halem.

Sandoval, M., \& Fuchs, C. (2010). Towards a critical theory of alternative media. Telematics and Informatics, 27, 141-150. doi:10.1016/j.tele.2009.06.011

Santos, S. C. (2013). Os média de serviço público. Covilhã: Livros LabCom.

Serrano, E. (2010). A especificidade do serviço público de televisão num contexto de fragmentação dos públicos e de multiplicação de plataformas. Jornalismos \& Jornalistas, 43, 5-17. 
Serrin, J., \& Serrin, W. (2002). Muckraking! The journalism that changed America. New York: The New Press.

Sharp, G. (2005). Waging nonviolent struggle. Boston, MA: Porter Sargent.

Shulman, S. W. (2009). The case against mass e-mails: Perverse incentives and low quality public participation in US federal rulemaking. Policy \& Internet, 1(1), 23-53. doi: $\underline{10.2202 / 1944-2866.1010}$

Singer, P. (2009). Animal Liberation. (1st Published in 1975). New York: Ecco Book/ Harper Perennial.

Sobral, F. A. (2012). Televisão em Contexto Português: uma abordagem histórica e prospetiva. Millenium, 42 (janeiro/junho), 143-159.

Syvertsen, T. (2003). Challenges to Public Television in the Era of Convergence and Commercialization. Television \& New Media, 4(2), 155-175. doi: $10.1177 / 1527476402250683$

Tornero, J., \& Varis, T. (2010). Media literacy and new humanism. UNESCO Institute for Information Technologies in Education.

Trappel, J., Meier, W., D'Haenens, L., Steemers, J. \& Thomass, B. (2011). Media in Europe Today. Bristol: Intellect.

Vicente, F. (2016). Novos media ou media tradicionais? O lugar da política num paradigma da comunicação em mudança. Cision Portugal. Retrieved from https:// www.cision.pt/2016/05/novos-media-ou-media-tradicionais-o-lugar-da-politica-num-paradigma-da-comunicac\%CC\%A7a\%CC $\% 830$-em-mudanc\%CC\%A7al

\section{Outras Fontes:}

EB88 || STANDARD EUROBAROMETER 88, (2017), "Media Use in the European Union”, Catalogue number NA-01-18-255-EN-N, ISBN 978-92-79-80983-5

DECLARAÇÃO UNIVERSAL DOS DIREITOS HUMANOS in Diário da República Portuguesa

Conspiracy \& Democracy Project (2018), YouGov and Cambridge University. 